\title{
IP3 - National Societies' Roles and Responsibilities
}

\author{
Roger G. Johnson \\ Birkbeck College, London University, UK, r.johnson@bcs.org.uk
}

\begin{abstract}
This paper discusses the nature of the global IT industry and explores the issues of attempting to impose minimum standards of competence, knowledge and conduct on such a disparate workforce. The paper proceeds to explain the rationale for the approach taken by the International Federation for Information Processing's (IFIP) International Professional Practice Partnership (IP3) and how it is being implemented. It is compared with the International Professional Engineer (IntPE) scheme of the International Engineering Alliance. Finally, the paper explains how IP3 understands that IITP will bring additional member benefits for IFIP member societies and also additional candidates coming forward to sit for suitable examinations offered by a arrange of third parties.
\end{abstract}

Keywords: International Professional Practice Partnership (IP3), International IT Practitioner (IITP), International Federation for Information Processing (IFIP), professional designation.

\section{Introduction}

This paper sets out the way in which the International Federation for Information Processing's (IFIP) International Professional Practice Partnership (IP3) operates its International IT Professional (IITP) programme. It explains why an international designation for IT professionals is needed. It will describe the operation of IITP and why IFIP and its member societies are uniquely placed to implement such a scheme. The paper explains the ambitions of the scheme and the need to build on what already exists. The paper concludes by outlining some of the prospective benefits from a successful implementation of such a scheme worldwide.

The International Federation for Information Processing (IFIP) is a global federation of over 55 member societies and, through its regional affiliates, linking almost 100 national IT bodies with an aggregate membership of almost 1 million individuals. 


\section{IT - the ultimate International Industry}

Modern advanced societies are entirely dependent for their quality of life on the IT industry - both supply and user sides. Developing nations are rightly keen to harness IT in support of achieving their development goals. The very large attendances at IFIP's two-yearly World IT Forum (WITFOR) conferences focussing specifically on how IT can be leveraged for development bear testimony to the universality of the ambition for IT-led solutions, [1].

No invention has transformed our world so comprehensively as the computer. It is only 60 years since the successful running of the world's first stored-program computer at Manchester University. From that pioneering work have flowed computer applications that touch all our lives every minute of every day.

The scale of the achievement comes from the ability to integrate computer technology with communications technology which together can deliver information almost instantaneously around the globe.

No other technology has advanced so fast. Every year new advances make possible information systems that were previously impractical. Building the vast systems that run on today's computers is an engineering activity that stands comparison with the greatest achievements of the nineteenth-century engineers who transformed that society. Modern information systems are now the most complex artefacts yet made by human beings.

\subsection{Ubiquitous IT}

Nothing illustrates the power of IT as well as the airline industry which so many of us have come to take for granted. Long gone are visits to travel agents to make bookings with many airlines now having over $80 \%$ of ticket sales online and many charging extra for telephone bookings.

E-tickets have replaced check-in desks apart from luggage drops. While we are going through security, the aircrew are agreeing their flight plans with Air Traffic Control, the aircraft is refuelled and the provisions for the flight are loaded, with details of the passengers' seats for special meals, all managed by a series of information systems.

When we board the aircraft we enter another world, where information systems rule. Increasingly for much of the flight the pilots do not fly the aircraft but monitor its behaviour against their preset flight plan.

Yet in the past few years airlines have been able to make further major advances. Minor faults detected by onboard systems on the previous flight and notified automatically to the destination can be quickly fixed so that aircraft can depart on schedule for their next flight. The latest aircraft have replaced many of the mechanical control systems with digital systems. 
One of the most remarkable aspects of this whole revolution is that the computer systems, apart from at the check in, are largely invisible to the passengers and yet without them mass commercial air transport would be impossible. Everywhere around us, at home with the telephone, car and domestic appliances, travelling to work by train and traffic control, and at work with all kinds of applications our lives are affected by information systems. In every case we barely notice their presence. Consequently IT practitioners have often been referred in articles to information systems engineers as 'invisible engineers'.

\subsection{Public Information Utility}

Starting from nowhere in the early 1990s, the Internet revolutionised the availability of information of all sorts. Companies rapidly advanced from just giving information to offering extensive e-business opportunities.

The Internet has become a public information utility. However, this introduces a crucial issue about designing and maintaining public information systems. The professionals who build and maintain such systems have a special responsibility of care in their construction. Like many other engineers, information systems engineers derive satisfaction from seeing others using the artefacts they have built. However, without understating the complexity of building a bridge, an information system is a much more complex artefact. In particular, the interaction between it and its user is far more complex.

Early computerised information systems often had several groups of employees between the computer and the customer. The modern system, such as one on the Internet, however, has no such intermediaries to check its output. Erroneous data supplied to Internet users may cause serious inconvenience.

\subsection{Professionalism}

Information systems professionals carry major responsibilities on their shoulders. This is why a career in information systems can be rewarding. But it is not to be undertaken lightly.

IT professionals have overcome a number of challenges in the past ten years, notably mostly avoiding problems from the "millennium bug" and the introduction of the euro throughout much of Europe. These two challenges provided serious challenges to information systems professionals. They also demonstrated another key attribute of information systems: information systems evolve. There are always changes to be made and facilities upgraded.

Information systems are at the heart of every developed society. They are essential to the standard of living we have all come to expect. Only properly trained professionals can ensure that the world has the information systems it needs to ensure the well-being of every citizen. 


\section{Regulating an International Profession}

To understand what it means to create a regulated profession we need first to understand the nature of the professional. The British Computer Society defines professionalism as:

A fully established IT professional is a practitioner who has specific skills rooted in a broad base and appropriate qualifications, belongs to a regulated body, undergoes continuous development, operates to a code of conduct and recognises personal accountability.

Thus to regulate IT professionals and thus to create a regulated profession it is essential to deal with each of the points in this definition. This means that there must be a means to:

- ensure that members of the community obtain and maintain an acceptable standard of professional competence

- define the profession's core body of knowledge and competences

- set appropriate minimum codes of conduct and professional standards set and enforce rules and standards which recognise and protect the public interest

- take disciplinary action should the rules and standards not be observed or should a member be guilty of unprofessional work

- support members in their commitment to adhere to the rules and professional standards

- provide sufficient capacity to implement and manage the above conditions

The historic professions have addressed these for many years. In the UK, the BCS has been accepted as a full member of the engineering community and BCS Professional Members can seek registration as a Chartered Engineer which is in turn fully recognized internationally. However, the UK is the only jurisdiction in which this has been achieved.

Implementations of professionalism vary from country to country and discipline to discipline. In some there are autonomous professional institutions while in others there are combinations of nationally approved qualifications and statutory regulation. IP3 does not advance any particular model but is concerned only that, whatever the mode in a given jurisdiction, the professional community can fulfill the minimum standards identified above.

For individual practitioners, who seek registration as a professional, this means that they must:

- conform to a published code of conduct

- know, and work within, the limits of their capabilities

- be accountable for and submit to peer review of their actions

- undertake continuous professional development 
- have their competence to practice re-assessed on a regular basis

- explain the implications of their work to stakeholders

- recognise obligations to the profession as well as to their employer

- have regard to the public good

- contribute to the development of the profession

- support other professionals in maintaining professional standards and developing professional competence

These requirements mean that any attempt to establish a global minimum standard for IT professionals must identify criteria to assess whether a member society operates appropriate procedures. These must cover, amongst other issues, individual knowledge compared to core body of knowledge, compliance with a Code of Conduct including an appropriate disciplinary procedure, together with availability and uptake of continuous professional development. Individuals also need to demonstrate their commitment to developing their profession and mutual support to fellow practitioners.

\section{How IITP will operate?}

The IP3 partners at their first meeting in Cape Town, ([2] includes a short background to the IP3 project to date), examined the challenge of creating a scheme for a global IT professional designation for individuals and recognised that it could only be done by a process of accrediting member societies to designate suitably qualified and experienced individual members.

Thus the Task Force recognised that it needed to establish accreditation criteria in each of the areas listed above as requirements of a regulated profession. The Task Force has recently produced an accreditation procedure which is the subject of another paper in this session.

IP3 will maintain a central register of all members of member societies who are eligible to use the designation International IT Practitioner (IITP).

The IP3 accreditation procedure applies to the procedures of the member body applying for accreditation and not to an individual. Typically member societies will seek accreditation for an existing grade of membership. Initially, this is expected to be Computer Professional (CP) by the Australian Computer Society (ACS), Chartered IT Practitioner (CITP) by the BCS and Information Systems Practitioner (ISP) by the Canadian Information Processing Society (CIPS).

If all are successful, it is expected that by autumn 2008 around 25,000 individuals will hold a member society designation which meets the IP3 criteria and hence be eligible to describe themselves as IITP.

The costs of operating IP3 will be met largely by an annual fee levied on the accredited organisations and which will reflect the number of individuals eligible to use the IITP designation. 


\section{Comparison with IntPE}

The IP3 international accreditation procedure is ambitious for a profession which has historically lacked even national standards. However, it has much in common with the procedures operated by the International Engineering Alliance (IEA), [3]. This body is responsible for the operation of the Washington Accord which, since 2001, "recognises substantial equivalence in the accreditation of qualifications in engineering technology" at tertiary level. They also operate a scheme for designating individuals as International Professional Engineers (IntPE) by a scheme which appears very similar to the proposed IP3 procedures for IITP.

At present IP3 does not have the equivalent of the Washington Accord but its standards for the tertiary level qualification are informed by BCS practice in this area which are compliant with the accord by reason of the BCS' membership of the UK Engineering Council which is a Washington Accord signatory.

Furthermore, IP3 is actively supporting the activities initiated in late 2007 to establish a "Seoul Declaration" which it is expected will achieve for computing courses what the Washington Accord has done for engineering courses.

Finally, the IEA shows that it is possible for a variety of different implementations of professionalism to cooperate successfully in promoting professional standards across the world in a robust manner.

\section{What IITP is not}

It is important to state several things which IP3 is not intending to do with IITP.

Firstly, it is not creating a new body to which individuals can belong. Individuals seeking the right to be designated an IITP must go to an IFIP member society and join at an appropriate grade. Thus IITP is an additional member benefit which should, if successful, lead to increased membership and higher levels of member retention.

Secondly, IP3 is not seeking to "re-invent wheels". Wherever possible, IP3 will seek to adopt existing material giving suitable acknowledgments to the original authors for granting the right to its use. For example, the Skills Framework for the Information Age (SFIA) has been adopted as the skills framework, [4].

Thirdly, IP3 is not an examining body. IP3 will set standards for member societies to apply to their members in terms of demonstrating competence with the Core Body of Knowledge and also with Continuing Professional Development (CPD). However, the way in which accredited bodies determine the competence of individuals they wish to designate is a matter for them. This could include traditional tertiary qualifications, which may in due course be covered by the "Seoul Declaration" or a combination of other qualifications, national or regional such as European Certification of Information Professionals, (EUCIP) [5]. What IITP accreditors will wish to ascertain is that alone or in combination they achieve 
the minimum standard set down. Again, IP3 believes that IITP can increase interest in professional and vocational qualifications to the benefit of a range of existing examining bodies.

Finally, IP3 is not yet another new body but a partnership amongst member societies in IFIP. All bodies seeking accreditation must be either Full Members or Professional Affiliates of IFIP.

\section{Conclusion}

IT is totally ubiquitous in our lives and increasingly worldwide, not just in developed countries. Consequently we are seeing the emergence of a uniquely global profession.

The mission of IP3 in promoting IITP is to offer the first global standard which IP3 member societies can use to designate suitably qualified and experienced individual practitioners as having achieved the right to describe themselves as an International IT Professional.

\section{References}

1. World IT Forum (WITFOR 2007), Addis Ababa, August 2007, www.witfor207.org

2. Hughes, C. International Professional Practice Partnership (IP3) - Overview. Proceeding of the WCC 2008 Professionalism Conference.

3. International Engineering Alliance, 2008 see www.washingtonaccord.org/

4. Skills Framework for the Information Age (SFIA), 2008 www.sfia.org.uk

5. European Certification of Information Professionals, (EUCIP), www.eucip.org 